\title{
Selected aspects of numerical modelling in prediction of building vibrations due to traffic
}

\author{
Stawomir Dudziak ${ }^{1, *}$, and Zofia Kozyra ${ }^{1}$ \\ ${ }^{1}$ Warsaw University of Technology, Faculty of Civil Engineering, ul. Lecha Kaczyńskiego 16, 00-637 \\ Warszawa, Poland
}

\begin{abstract}
Dynamic analyses play an important role in the process of designing buildings in the vicinity of transportation routes. The Finite Element Method is the most popular modelling technique, because it allows to simulate the structure response in the higher frequency range properly. However, the results of such analyses depend on many factors and can differ a lot. This paper discusses the impact of the building mass estimation and neglecting or including damping in the analysis on the assessment of influence of vibrations due to traffic on people.
\end{abstract}

\section{Introduction}

Parallel development of residential areas and transportation routes often results in their vicinity. Moving vehicles induce mechanical waves, which are transferred by subsoil to building foundations. This excites vibrations of their structures, which can cause an increase in internal forces or a feeling of discomfort amongst their users [1]. An analysis that aims to predict the level of these vibrations should be a part of the design process. In the case of a high possibility that this levels may exceed comfort limits (in Poland they are defined by the standard [2]), suitable vibration reduction means can be introduced.

The main part of such an analysis is computer simulations, in which the Finite Element Method (FEM) is now being used [3]. The preparation of a detailed model is necessary in order to simulate the structure response in a range of higher frequencies properly, because they dominate in excitation caused by moving vehicles. The amendment to the Polish standard from 2017 [2] introduced a demand for using FEM modelling in case of such an analysis. However, the standard does not contain information about details like a preferable model of damping or mass distribution, which may have an important influence on the results of the vibration prediction.

When the analysis concerns an existing building, the model validation should be performed using the results of in situ measurements. Measurement points should be located: in the soil next to foundations, on the foundations and in the upper parts of the building. The first two points allow identifying the transfer function, which describes how vibration characteristics change at the interface of the foundation. The example of such a function can be found in the paper [4]. The accelerograms registered on the foundation can be used

\footnotetext{
*Corresponding author: s.dudziak@ili.pw.edu.pl
} 
as kinematic excitation in the dynamic analysis (like in [5 - 6]). The response of the model in the upper points of the building may be confronted with response of the real building.

Unfortunately, this algorithm cannot be used during the design stage. What is more, in at this point many serious decisions have to be made. The wrong prediction of the vibration level may result in complaints from future users (underestimation) or unnecessary costs of vibration insulation (overestimation).

This paper discusses the influence of the mass distribution and damping parameters on the results of the dynamic analysis and the assessment of the impact of vibrations on people.

\section{Model and assessment methodology description}

The analysed building has three above-ground storeys and an underground car park. Its main structure is made of reinforcement concrete. The slabs are stiffened with ribs and the staircase allows vertical communication. The FEM model of the building was prepared in the Abaqus software [7]. Shell (S4R) and beam (B33) elements were used. The model consisted of about 18000 elements connected in about 19000 nodes, the total number of variables in the model was about 112 000. The following mechanical properties were adopted for concrete: Young modulus $\mathrm{E}=32 \mathrm{GPa}$, Poisson ratio $v=0.2$, density $\rho=2500$ $\mathrm{kg} / \mathrm{m}^{3}$. The model and the adopted mesh are presented in Figure 1.
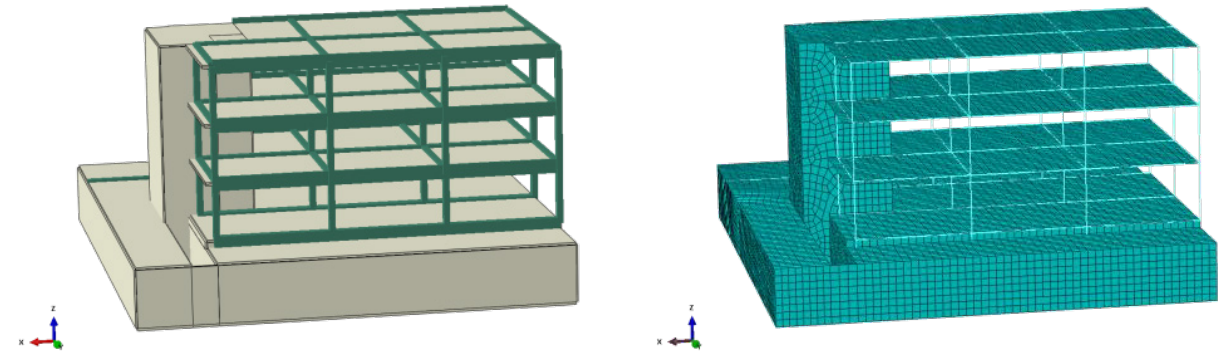

Fig. 1. The building model and the mesh adopted in the analysis.

Three mass distributions recommended by the Polish standard [8] in the assessment of vibrations influence on the structure and connected with different stages of the building life, were examined:

- A - self-weight of the main structure,

- B - self-weight of the main structure + weight of finishing layers (dead load),

- $\mathrm{C}$ - self-weight of the main structure + weight of finishing layers (dead load) + 0.4 live load.

The modal and dynamic analyses were performed with the above mentioned mass distributions. The former used the Lanczos algorithm. The latter based on the HilberHughes-Taylor method, which is one of direct integration of the motion equation methods. The length of one step was $0.002 \mathrm{~s}$. The accelerograms registered in the proximity of the first Warsaw underground line were used as the kinematic excitation. They are presented in Figure 2. The transfer function was not used because the aim of this paper is to compare different models rather than to asses a real design. In addition, each mass distribution was analysed with and without damping. The Rayleigh proportional damping, which is the most popular due to its simplicity $[6,9,10]$, was adopted in the analysis. In order to ensure 
damping ratio not exceeding 0.03 of critical damping in the frequency range of interest $(0.8-115 \mathrm{~Hz})$, the following values were introduced in the analysis: $\alpha=0.372$ and $\beta=0.000118$.

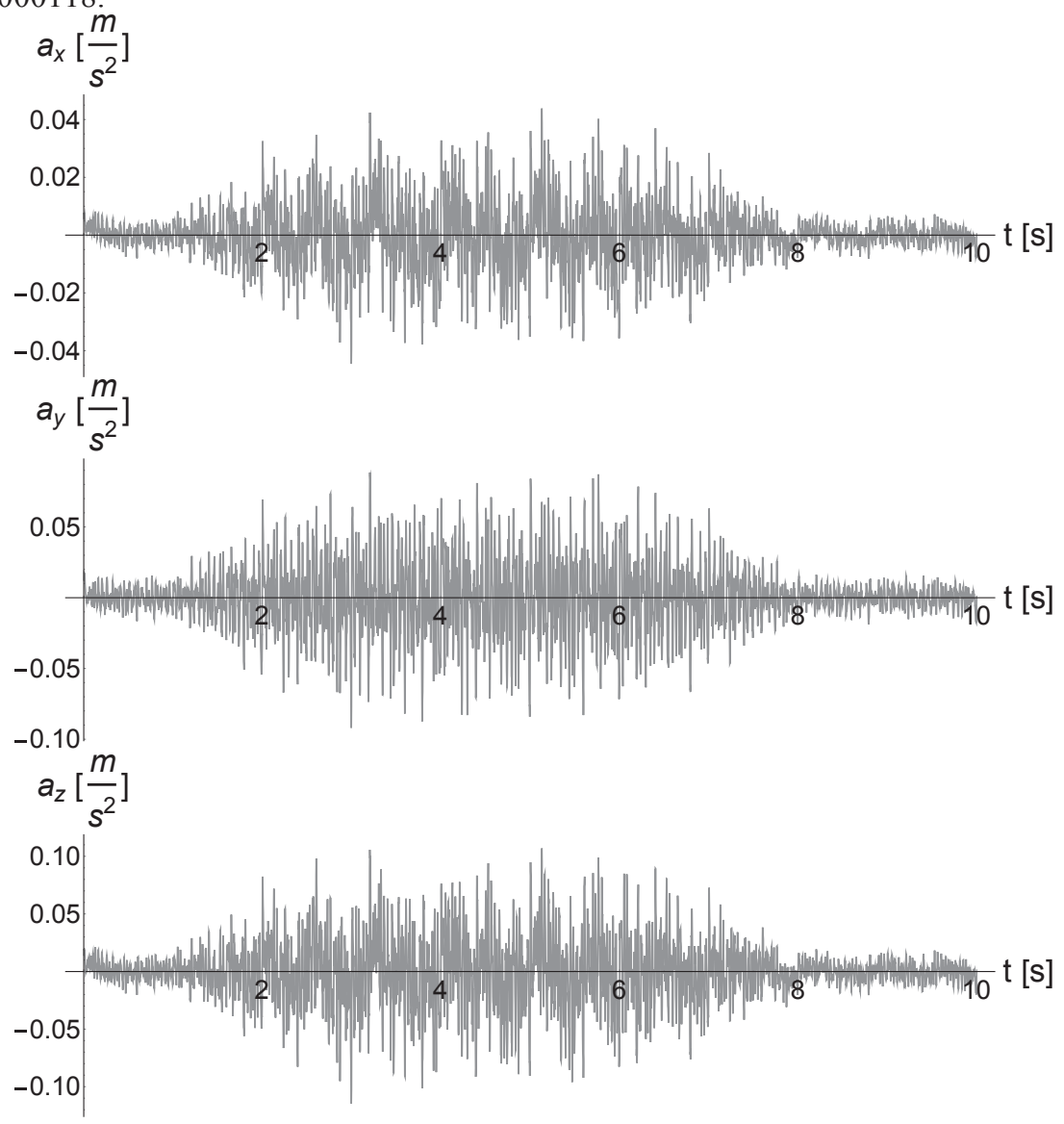

Fig. 2. The accelerograms used as kinematic exctitaion.

The last step was signal processing, which was conducted with Mathematica software. Signals obtained from the dynamic analysis for each slab were divided into one-third octave bands. The root mean square $(R M S)$ value was calculated for each band and compared with the vibration threshold perceptibility. For each analysed case, the WODL factor defined in the standard [2] and concerning only vertical direction was determined. This factor consists of two values: the maximum quotient of the RMS by the vibration threshold and the band in which this maximum occurs. The signal processing includes determining the vibration duration defined in the Polish standard [2] as the time between 0.2 amplitude of the peak value. The response registered in points on columns were transformed into frequency domain using the Fast Fourier Transform algorithm.

\section{Modal analysis results}

In Table 1 first twenty natural frequencies for each mass distribution are compared. In Figures 3 and 4 the chosen eigenvectors are presented for model A. For the other two, the eigenvectors do not differ a lot. 
Table 1. Eigenvalues for mass distributions A, B and C.

\begin{tabular}{|c|c|c|c|}
\hline \multirow{2}{*}{ No } & \multicolumn{3}{|c|}{$\mathrm{f}[\mathrm{Hz}]$} \\
\cline { 2 - 4 } & mass A & mass B & mass C \\
\hline 1 & 3.59 & 3.20 & 3.12 \\
\hline 2 & 5.75 & 5.28 & 5.18 \\
\hline 3 & 7.63 & 5.81 & 5.81 \\
\hline 4 & 8.26 & 7.24 & 7.07 \\
\hline 5 & 9.19 & 8.33 & 8.00 \\
\hline 6 & 9.76 & 8.98 & 8.60 \\
\hline 7 & 10.01 & 9.11 & 8.67 \\
\hline 8 & 10.43 & 9.25 & 8.79 \\
\hline 9 & 10.64 & 9.50 & 8.96 \\
\hline 10 & 10.84 & 9.56 & 9.27 \\
\hline 11 & 10.93 & 9.61 & 9.39 \\
\hline 12 & 11.12 & 9.87 & 9.58 \\
\hline 13 & 11.18 & 10.14 & 9.65 \\
\hline 14 & 11.83 & 10.21 & 9.74 \\
\hline 15 & 12.02 & 10.32 & 9.93 \\
\hline 16 & 12.12 & 10.64 & 10.15 \\
\hline 17 & 12.17 & 10.69 & 10.29 \\
\hline 18 & 12.24 & 10.84 & 10.37 \\
\hline 19 & 12.44 & 10.88 & 10.44 \\
\hline 20 & 12.81 & 11.01 & 10.55 \\
\hline
\end{tabular}
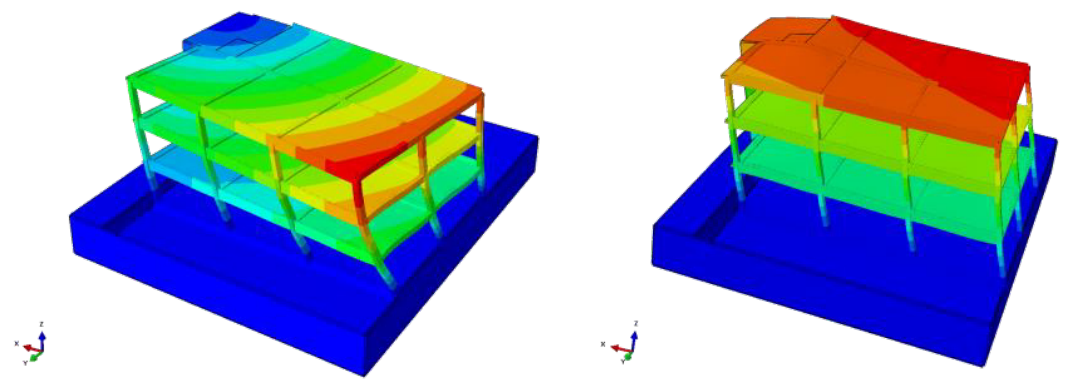

Fig. 3. The first two normal modes of the analysed building.
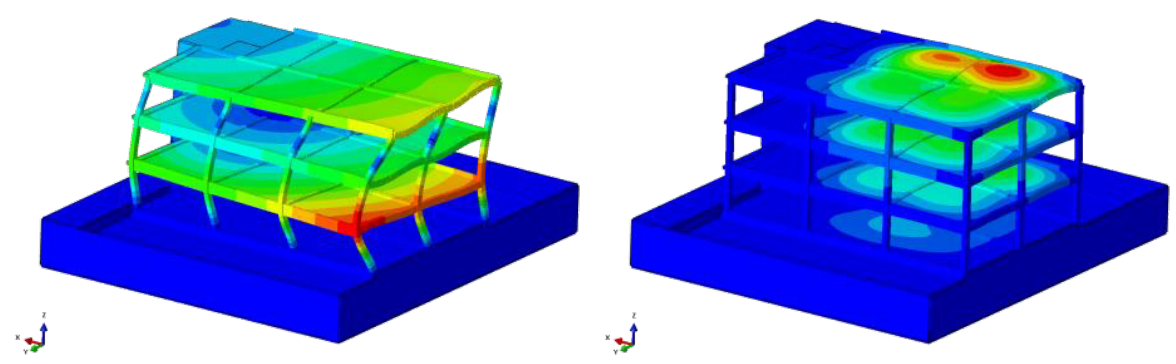

Fig. 4. The normal modes 4 and 5 of the analysed building. 


\section{Dynamic analysis results}

In table 2 WODL factors for each analysed case are compared. The RMS bars for the $2^{\text {nd }}$ floor are presented in Figures 5 and 6.

Table 2. WODL factors for analysed models.

\begin{tabular}{|c|c|c|c|c|}
\hline \multirow{2}{*}{ Mass distribution } & \multicolumn{2}{|c|}{ WODL } & \multirow{2}{*}{ Floor } \\
\cline { 3 - 5 } & value & band & \\
\hline \multirow{2}{*}{ A } & Without damping & 66.7 & $31.6 \mathrm{~Hz}$ & 1 \\
\cline { 2 - 5 } & With damping & 10.2 & $12.5 \mathrm{~Hz}$ & 1 \\
\hline \multirow{2}{*}{$\mathrm{B}$} & Without damping & 23.5 & $10 \mathrm{~Hz}$ & 1 \\
\cline { 2 - 5 } & With damping & 14.5 & $8 \mathrm{~Hz}$ & 2 \\
\hline \multirow{2}{*}{$\mathrm{C}$} & Without damping & 41.4 & $25 \mathrm{~Hz}$ & 0 \\
\cline { 2 - 5 } & With damping & 25.8 & $8 \mathrm{~Hz}$ & 2 \\
\hline
\end{tabular}

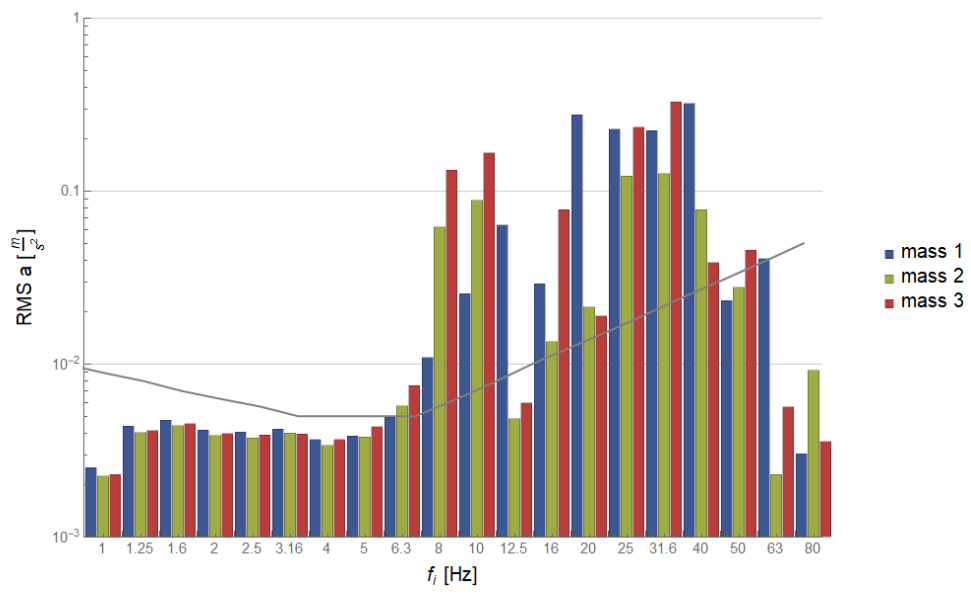

Fig. 5. The RMS bars for different masses, the analysis neglecting damping, floor 2, vertical direction.

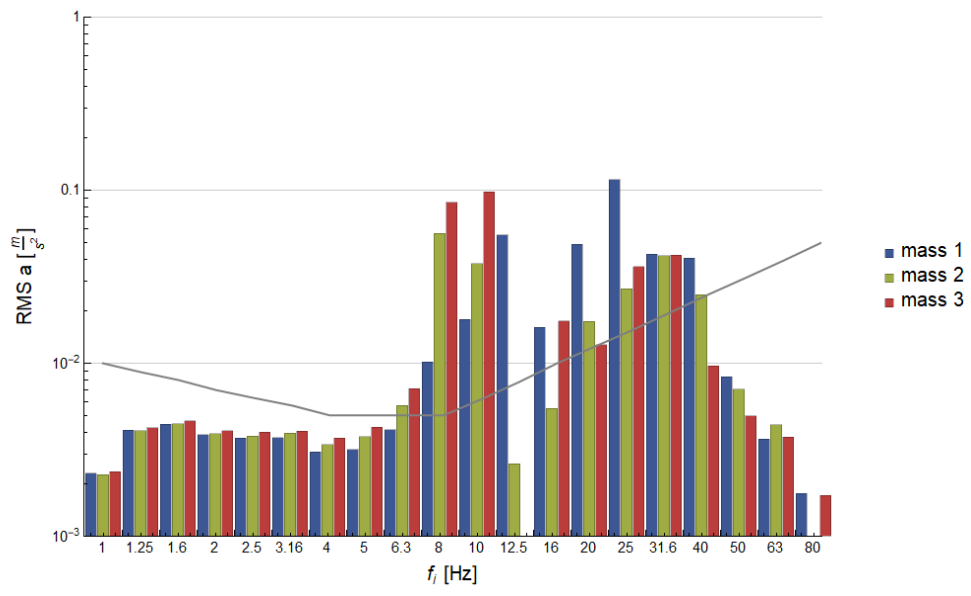

Fig. 6. The RMS bars for different masses, the analysis including damping, floor 2, vertical direction. 
In Figure 7 the exemplary response in the time domain in vertical direction for mass $\mathrm{C}$ registered on the column of last floor is presented. Whereas, in figure 8 the response in the frequency domain is compared for different mass distributions.

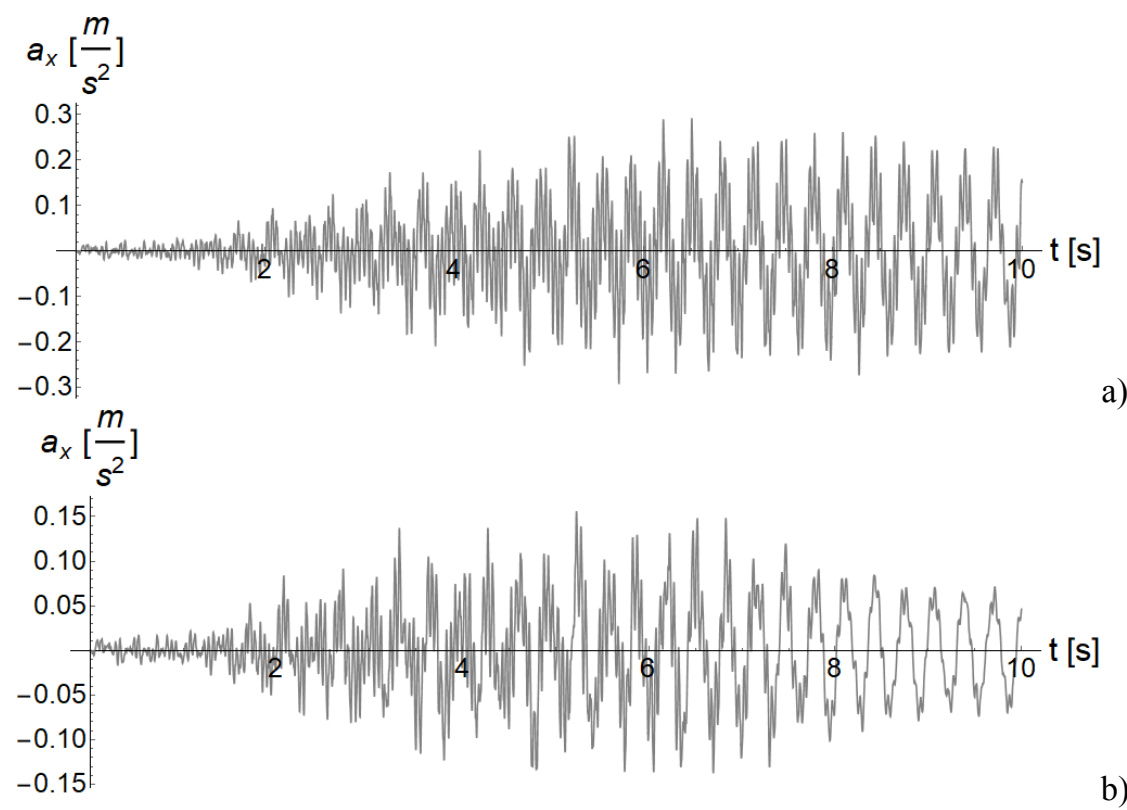

Fig. 7. The vibrations of the last floor column in the time domain: a) without damping, b)including damping.

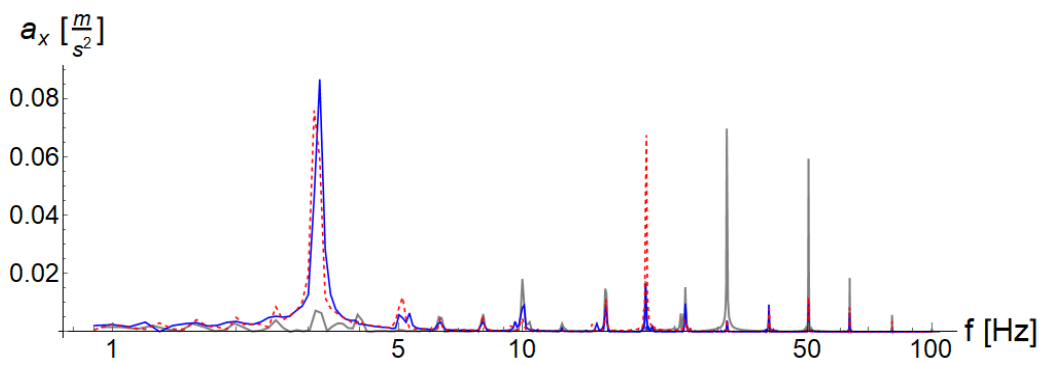

\section{$a_{x}\left[\frac{m}{s^{2}}\right]$}

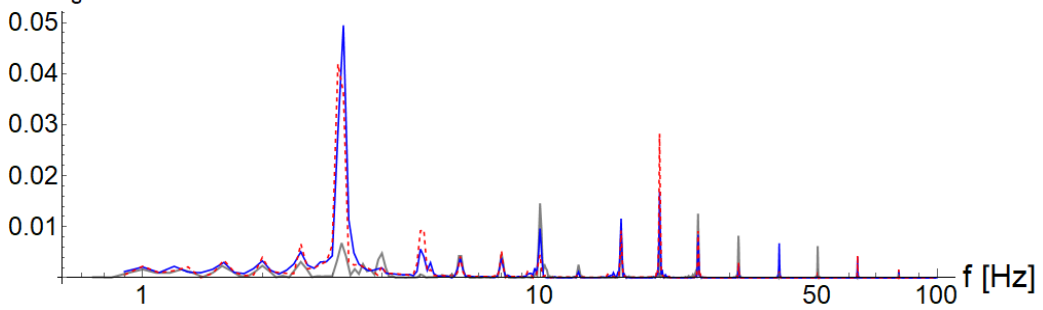

Fig. 8. The vibrations of the last floor column in the frequency domain: a) without damping, b)including damping. 


\section{Summary}

As the mass of the building increases, the natural frequencies decrease, which is fairly obvious. This usually makes the building less sensitive to kinematic excitation due to transportation, in which higher frequencies dominate.

The analysis of the building at the stage, when only main structure is ready without including its damping properties sometimes leads to the unrealistically high amplitudes of vertical slabs vibrations in the higher frequency range (compare Table 1). For mass distributions $\mathrm{B}$ and $\mathrm{C}$ differences in responses of the structures with and without damping are noticeable, but not as much as in the case of distribution A.

On the other hand, for the mass distributions B and C, the amplifications in the lower frequency range can be observed (compare figure 8), which can have great importance for internal forces values in the structure.

Another observation is that if we neglect damping, it could be impossible to fulfil the guidelines of the standard [2] concerning the duration of vibrations, because the amplitudes may not reach the level of 0.2 peak value (compare Figure 7).

To sum up, different mass distributions should be examined during the analysis of the vibration influence on the building and its users at the design stage. The addition of clear guidelines how to include damping to the standards, would be beneficial and allow the unification of results amongst different centres. As was shown in this paper, damping parameters are great of importance for the results of the assessment. There are many another factors which may influence the assessment (like the correctness of transfer functions or changes in the soil conditions due to the construction process), so in case of the building in the immediate vicinity of vibration sources, the control measurements during the construction process and before the introduction of residents, should be performed.

\section{References}

1. R. Ciesielski, Ocena szkodliwości wpływów dynamicznych w budownictwie (Warszawa, 1973, in Polish)

2. PN-B-02171:2017-06 Ocena wpływu drgań na ludzi w budynkach (in Polish)

3. A. Zbiciak, Z. Kozyra, R. Czubacki, S. Dudziak, R. Michalczyk, Inżynieria i Budownictwo, 8, 433-436 (2017, in Polish)

4. T. Chyży, Prace Instytutu Techniki Budowlanej, 1, 19-41 (2008) (in Polish)

5. A. Zbiciak, Z. Kozyra, K. Józefiak, TTS Technika Transportu Szynowego, 9, 1-9 (2012) (in Polish)

6. M. Miśkiewicz, Ł. Pyrzowski, M. Rucka, K. Wilde, J. Chróścielewski, Archives of Civil Engineeirng, 3, 85-97 (2017)

7. Abaqus Theory Manual (Dassault Systèmes, 2012)

8. PN-B-02170:2016-12 Ocena szkodliwości drgań przekazywanych przez podłoże na budynki

9. K.J. Bathe, Finite element procedures (Prentice Hall, 1996)

10. H. Zobel, A. Zbiciak, R. Oleszek, R. Michalczyk, P. Mossakowski, Roads and Bridges, 13, 189-215 (2014) 